\title{
Erratum to: Real-time ultrasound-guided PCNL using a novel SonixGPS needle tracking system
}

\author{
Xiang Li • Qingzhi Long $\cdot$ Xingfa Chen $\cdot$ Dalin He \\ Hui He
}

Published online: 23 August 2014

(C) Springer-Verlag Berlin Heidelberg 2014

Erratum to: Urolithiasis (2014) 42:341-346

DOI 10.1007/s00240-014-0671-2

In the original article, one of the co-author's (Dalin He) given name and family name are represented incorrectly. The correct name should be Dalin He.

The online version of the original article can be found under doi:10.1007/s00240-014-0671-2.

X. Li $\cdot$ Q. Long $\cdot$ X. Chen $\cdot$ D. He $\cdot H . H e(\triangle)$

Department of Urology, First Affiliated Hospital,

Xi' an Jiaotong University, No. 277 Yanta West Road,

Xi' an 710061, Shaanxi, China

e-mail: hhurologistlx@163.com; urologistlx@163.com 